\title{
Efficacy and Safety of Ezetimibe Added to Atorvastatin Versus Atorvastatin Uptitration or Switching to Rosuvastatin in Patients With Primary Hypercholesterolemia
}

\author{
Harold E. Bays, MD ${ }^{\mathrm{a}, *}$, Maurizio Averna, MD ${ }^{\mathrm{b}}$, Claudio Majul, MD ${ }^{\mathrm{c}}$, Dirk Muller-Wieland, MD ${ }^{\mathrm{d}}$, \\ Annamaria De Pellegrin, MD ${ }^{\mathrm{e}}$, Hilde Giezek, $\mathrm{MSc}^{\mathrm{f}}$, Raymond Lee, BS ${ }^{\mathrm{g}}$, Robert S. Lowe, $\mathrm{PhD}^{\mathrm{g}}$, \\ Philippe Brudi, $\mathrm{MD}^{\mathrm{g}}$, Joseph Triscari, $\mathrm{PhD}^{\mathrm{g}}$, and Michel Farnier, $\mathrm{MD}, \mathrm{PhD}^{\mathrm{h}}$
}

\begin{abstract}
Hypercholesterolemic patients $(n=1,547)$ at high atherosclerotic cardiovascular disease risk with low-density lipoprotein cholesterol (LDL-C) levels $\geq 100$ and $\leq 160 \mathrm{mg} / \mathrm{dl}$ while treated with atorvastatin $10 \mathrm{mg} /$ day entered a multicenter, randomized, double-blind, activecontrolled, clinical trial using two 6-week study periods. Period I compared the efficacy/safety of (1) adding ezetimibe $10 \mathrm{mg}$ (ezetimibe) to stable atorvastatin $10 \mathrm{mg}$, (2) doubling atorvastatin to $20 \mathrm{mg}$, or (3) switching to rosuvastatin $10 \mathrm{mg}$. Subjects in the latter 2 groups who persisted with elevated LDL-C levels ( $\geq 100$ and $\leq 160 \mathrm{mg} / \mathrm{dl}$ ) after period I, entered period II; subjects on atorvastatin $20 \mathrm{mg}$ had ezetimibe added to their atorvastatin $20 \mathrm{mg}$, or uptitrated their atorvastatin to $40 \mathrm{mg}$; subjects on rosuvastatin $10 \mathrm{mg}$ switched to atorvastatin $20 \mathrm{mg}$ plus ezetimibe or uptitrated their rosuvastatin to $20 \mathrm{mg}$. Some subjects on atorvastatin $10 \mathrm{mg}$ plus ezetimibe continued the same treatment into period II. At the end of period I, ezetimibe plus atorvastatin $10 \mathrm{mg}$ reduced LDL-C significantly more than atorvastatin $20 \mathrm{mg}$ or rosuvastatin $10 \mathrm{mg}(22.2 \%$ vs $9.5 \%$ or $13.0 \%$, respectively, $\mathrm{p}<0.001)$. At the end of period II, ezetimibe plus atorvastatin $20 \mathrm{mg}$ reduced LDL-C significantly more than atorvastatin $40 \mathrm{mg}(17.4 \% \mathrm{vs}$ $6.9 \%, \mathrm{p}<0.001$ ); switching from rosuvastatin $10 \mathrm{mg}$ to ezetimibe plus atorvastatin $20 \mathrm{mg}$ reduced LDL-C significantly more than uptitrating to rosuvastatin $20 \mathrm{mg}(17.1 \%$ vs $7.5 \%$, $\mathrm{p}<0.001)$. Relative to comparative treatments, ezetimibe added to atorvastatin $10 \mathrm{mg}$ (period I) or atorvastatin $20 \mathrm{mg}$ (period II) produced significantly greater percent attainment of LDL-C targets $<100$ or $<70 \mathrm{mg} / \mathrm{dl}$, and significantly greater percent reductions in total cholesterol, non-high-density lipoprotein cholesterol, most lipid and lipoprotein ratios, and apolipoprotein B (except ezetimibe plus atorvastatin 20 vs atorvastatin $40 \mathrm{mg}$ ). Reports of adverse experiences were generally similar among groups. In conclusion, treatment of hypercholesterolemic subjects at high cardiovascular risk with ezetimibe added to atorvastatin 10 or $20 \mathrm{mg}$ produced significantly greater improvements in key lipid parameters and significantly greater attainment of LDL-C treatment targets than doubling atorvastatin or switching to (or doubling) rosuvastatin at the compared doses. (C) 2013 Elsevier Inc. All rights reserved. (Am J Cardiol 2013;112:1885-1895)
\end{abstract}

Few studies have used treat-to-target designs that compare sequential "real-life" treatment options in lipid management among the most challenging patients,

\footnotetext{
${ }^{\mathrm{a}}$ Louisville Metabolic and Atherosclerosis Research Center, Louisville, Kentucky; ${ }^{\mathrm{b}}$ University of Palermo, Palermo, Italy; ${ }^{\mathrm{c}}$ Hospital General de Agudos Donación Francisco Santojanni, Buenos Aires, Argentina; ${ }^{\mathrm{d}}$ Asklepios Hospital St. Georg, Medical Faculty of Semmelweis University, Hamburg, Germany; ${ }^{e}$ Presidio Ospedaliero di Vittorio Veneto, Vittorio Veneto, Italy; ${ }^{\mathrm{f}}$ MSD Belgium, Brussels, Belgium; ${ }^{\mathrm{g}}$ Merck \& Co. Inc., Whitehouse Station, New Jersey; and ${ }^{\mathrm{h}}$ Point Médical, Dijon, France. Manuscript received June 10, 2013; revised manuscript received and accepted August 6, 2013.

Merck \& Co. (Whitehouse Station, New Jersey) provided financial support for the conduct of this study.

This study (MK653C in High Cardiovascular Risk Patients with High Cholesterol) is registered at ClinicalTrials.gov (NCT01154036).

See page 1894 for disclosure information.

*Corresponding author: Tel: (502) 515-5672; fax: (502) 214-3999.

E-mail address: hbaysmd@aol.com (H.E. Bays).
}

including those at high cardiovascular disease (CVD) risk with intensive low-density lipoprotein cholesterol (LDL-C) treatment targets. This 2-period study (each 6 weeks) examined patients at high CVD risk who did not achieve LDL-C targets while treated with a commonly prescribed statin at a commonly used dose (atorvastatin $10 \mathrm{mg} /$ day). The primary objective of period I was to compare the LDLC-lowering efficacy of ezetimibe $10 \mathrm{mg}$ add-on to atorvastatin $10 \mathrm{mg}$ versus doubling atorvastatin to $20 \mathrm{mg}$ or switching to rosuvastatin $10 \mathrm{mg}$. The main objective of period II was to examine subjects who did not achieve an LDL-C target of $<100 \mathrm{mg} / \mathrm{dl}$ after period I, compare the LDL-C-lowering efficacy of adding ezetimibe $10 \mathrm{mg}$ to atorvastatin $20 \mathrm{mg}$ versus doubling the atorvastatin dose from $20 \mathrm{mg}$ (period I) to $40 \mathrm{mg}$, and compare switching from rosuvastatin $10 \mathrm{mg}$ (period I) to ezetimibe $10 \mathrm{mg}$ plus atorvastatin $20 \mathrm{mg}$ versus doubling rosuvastatin to $20 \mathrm{mg}$. Finally, this study evaluated these sequential treatment options with regard to achievement of LDL-C treatment targets of $<100$ or $<70 \mathrm{mg} / \mathrm{dl}$, consistent with National 


\begin{tabular}{|c|c|c|}
\hline & $\mathrm{EZ} 10 \mathrm{mg}+$ Atorva $10 \mathrm{mg} \quad(\mathrm{n}=90)$ & \multirow[b]{2}{*}{ EZ 10mg + Atorva $10 \mathrm{mg} \quad(n=28)$} \\
\hline & $\mathrm{EZ} 10 \mathrm{mg}+$ Atorva $10 \mathrm{mg} \quad(n=30)$ & \\
\hline & Atorva $20 \mathrm{mg} \quad(n=243)$ & $E Z 10 m g$ + Atorva $20 \mathrm{mg} \quad(n=124)$ \\
\hline \multirow{3}{*}{ Atorva $10 \mathrm{mg} \mathrm{(N=2646)}$} & Atorva $20 \mathrm{mg} \quad(n=240)$ & Atorva $40 \mathrm{mg}$ \\
\hline & Rosuva $10 \mathrm{mg} \quad(n=468)$ & $E Z 10 \mathrm{mg}+$ Atorva $20 \mathrm{mg} \quad(\mathrm{n}=234)$ \\
\hline & Rosuva 10mg $(n=476)$ & Rosuva $20 \mathrm{mg}$ \\
\hline
\end{tabular}

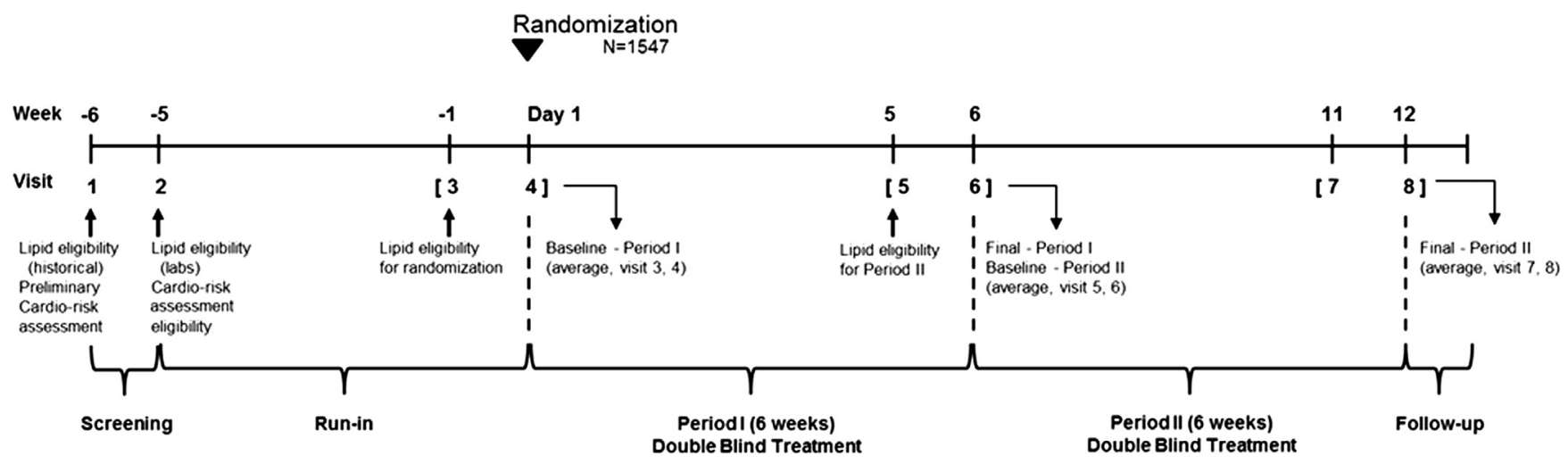

Figure 1. Study design. Atorva $=$ atorvastatin; $\mathrm{EZ}=$ ezetimibe; Rosuva $=$ rosuvastatin.

Cholesterol Education Program, Adult Treatment Panel III and European Society of Cardiology/European Atherosclerosis Society guidelines. ${ }^{1,2}$

\section{Methods}

This clinical trial entitled A Randomized, Double-Blind, Active-Controlled, Multicenter Study of Patients with Primary Hypercholesterolemia and High Cardiovascular Risk Who Are Not Adequately Controlled with Atorvastatin $10 \mathrm{mg}$ : A Comparison of the Efficacy and Safety of Switching to Coadministration Ezetimibe and Atorvastatin Versus Doubling the Dose of Atorvastatin or Switching to Rosuvastatin (PACE), was conducted from September 29, 2010 to October 17, 2012 (study MK653C-162, http:// clinicaltrials.gov, identifier NCT01154036) and included subjects evaluated from 296 research sites across 29 countries (Argentina [18], Belgium [2], Bulgaria [11], Canada [15], Chile [7], Columbia [5], Croatia [4], Czech Republic [19], Denmark [5], Estonia [4], Finland [5], France [7], Germany [9], Hungary [13], Israel [14], Italy [8], Lithuania [8], the Netherlands [4], Norway [4], Poland [14], Portugal [4], Romania [18], Slovakia [12], Slovenia [3], Spain [11], Sweden [6], Turkey [8], the United Kingdom [12], and the United States [46]). The study was conducted in accordance with principles of the ICH Good Clinical Practice and all local and/or national regulations and directives. The appropriate institutional review boards approved the protocol, and all subjects documented their agreement to participate by written informed consent.

Subjects included in the present study were men and women of nonchildbearing potential and aged $\geq 18$ and
$<80$ years with primary hypercholesterolemia. Subjects were required to be at high CVD risk and meet prespecified lipid entry criteria. The high CVD risk study entry criteria included subjects without CVD who had type 2 diabetes mellitus or $\geq 2$ CVD risk factors and a 10-year risk for coronary heart disease $>20 \%$ (as determined by the Framingham risk calculation) or subjects with known CVD, including patients with established coronary and other atherosclerotic vascular diseases. $^{2-4}$ The lipid study entry criteria included subjects naive to lipid-lowering therapy (never treated or no therapy for $\geq 6$ weeks before the prescreen visit) with an LDL-C level in the predetermined range of 166 to $190 \mathrm{mg} / \mathrm{dl}$ or subjects on a stable dose of statin, ezetimibe, or statin plus ezetimibe having LDL-C-lowering efficacy equivalent to or less than atorvastatin $10 \mathrm{mg}$ and with historic lipid values within a range that might reasonably meet randomization lipid criteria (described later).

Main exclusion criteria included alanine aminotransferase or aspartate aminotransferase levels $>2 \times$ the upper limit of normal (ULN); creatine kinase $>3 \times$ the ULN; a history of significant myopathy or rhabdomyolysis with any statin or ezetimibe; hypersensitivity or intolerance to ezetimibe, atorvastatin, rosuvastatin, or any component of these medications; congestive heart failure (New York Heart Association class III or IV); previous myocardial infarction, coronary artery bypass surgery, angioplasty, or acute coronary syndrome within 3 months before screening; uncontrolled cardiac arrhythmias or recent significant changes on an electrocardiogram within 6 months before screening; homozygous familial hypercholesterolemia or LDL-C apheresis; partial ileal bypass, gastric bypass, or other significant intestinal malabsorption; uncontrolled hypertension; poorly controlled type 1 or 2 diabetes 


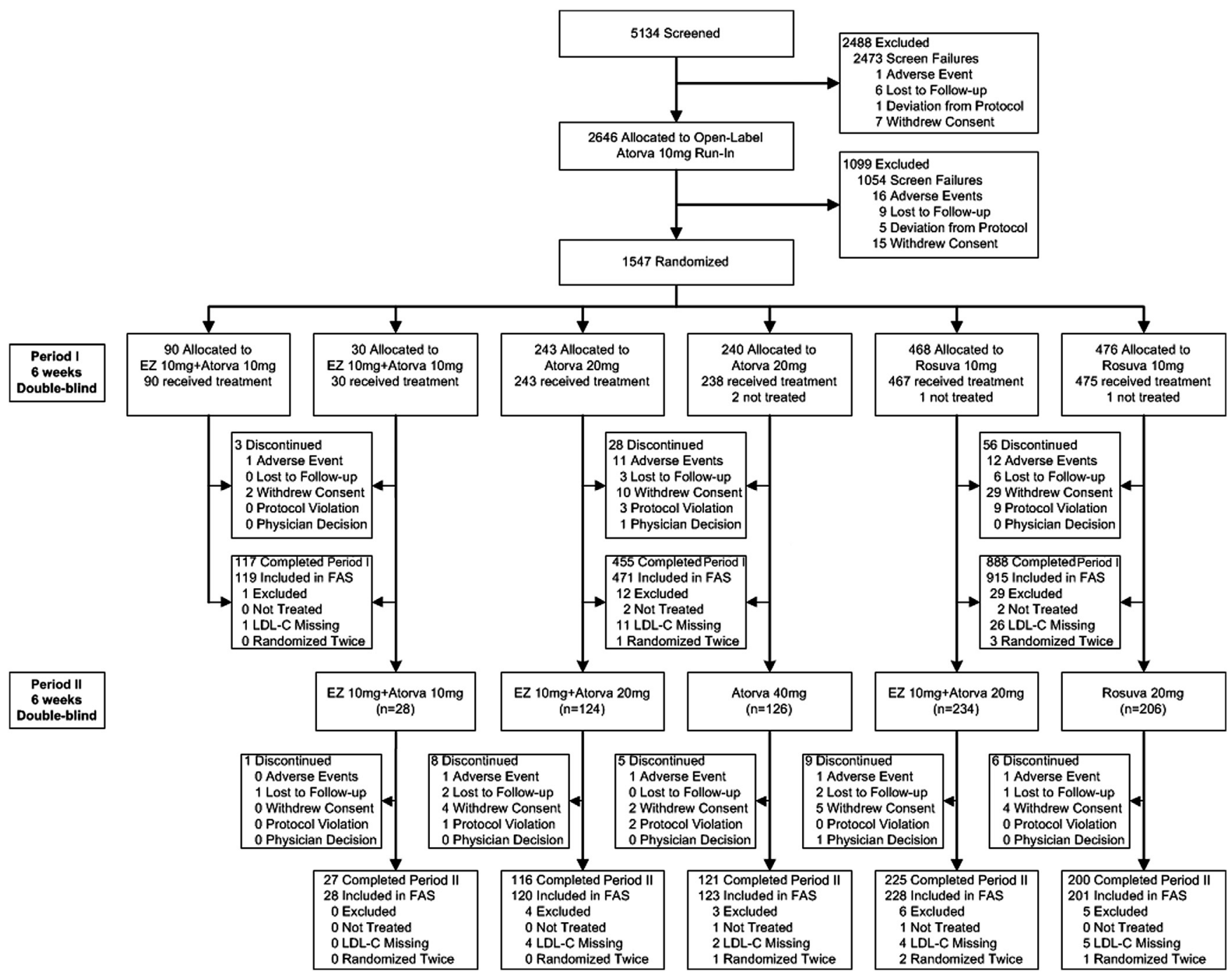

Figure 2. Participant distribution. Atorva $=$ atorvastatin; $\mathrm{EZ}=$ ezetimibe; FAS $=$ full analysis set (includes all randomized patients with baseline and at least 1 valid postbaseline evaluation); Rosuva $=$ rosuvastatin.

mellitus (defined by HbA1c $\geq 8.5 \%$ ); estimated glomerular filtration rate $<30 \mathrm{ml} / \mathrm{min} / 1.73 \mathrm{~m}^{2}$ based on the 4 -variable Modification of Diet in Renal Disease equation, nephrotic syndrome, or other clinically significant renal disease; active liver disease; uncontrolled endocrine or metabolic disease known to influence serum lipids or lipoproteins; disorders of the hematologic, digestive, or central nervous systems including cerebrovascular disease (e.g., stroke, transient ischemic attack) and degenerative disease that would limit study evaluation or participation.

After study entry, lipid-altering drug-naïve subjects were administered open-label atorvastatin $10 \mathrm{mg} /$ day. For subjects previously treated with lipid-altering drugs, these lipidaltering drugs were discontinued, and the subjects were switched to open-label atorvastatin $10 \mathrm{mg} /$ day. After 5 weeks of open-label atorvastatin $10 \mathrm{mg} /$ day, subjects were required to meet a second set of randomization entry criteria which included LDL-C levels $\geq 100$ and $\leq 160 \mathrm{mg} / \mathrm{dl}$ and triglyceride levels $\leq 400 \mathrm{mg} / \mathrm{dl}$. Subjects meeting these criteria were randomized to 1 of 6 blinded treatment sequences in a 3:1:8:8:16:16 ratio based on sample size assumptions (see later), which determined treatment in period I (first 6 weeks) and period II (second 6 weeks) of the study (Figure 1). Treatment during period I included (1) adding ezetimibe $10 \mathrm{mg}$ to stable atorvastatin $10 \mathrm{mg}$ therapy, (2) doubling atorvastatin to $20 \mathrm{mg}$, or (3) switching to rosuvastatin $10 \mathrm{mg}$. Subjects in the latter 2 groups who persisted with LDL-C levels $\geq 100$ and $\leq 160 \mathrm{mg} / \mathrm{dl}$ at the end of period I entered period II; subjects on atorvastatin $20 \mathrm{mg}$ received atorvastatin $20 \mathrm{mg}$ plus ezetimibe $10 \mathrm{mg}$ or atorvastatin uptitrated to $40 \mathrm{mg}$; those on rosuvastatin $10 \mathrm{mg}$ were switched to atorvastatin $20 \mathrm{mg}$ plus ezetimibe $10 \mathrm{mg}$ or uptitrated to rosuvastatin $20 \mathrm{mg}$. Approximately $25 \%$ of those receiving atorvastatin $10 \mathrm{mg}$ plus ezetimibe during period I continued into period II irrespective of LDL-C levels to maintain study blinding. Randomization was performed using a central interactive voice response system. All study personnel, including investigators, study site personnel, patients, monitors, and central laboratory personnel, remained blinded to treatment allocation throughout the study; the final database 
Table 1

Baseline characteristics (all randomized subjects)

\begin{tabular}{|c|c|c|c|c|c|c|c|c|}
\hline \multirow[t]{2}{*}{ Characteristic } & \multicolumn{3}{|c|}{ Period I } & \multicolumn{5}{|c|}{ Period II } \\
\hline & $\begin{array}{c}\mathrm{E} 10+\mathrm{A} 10 \\
(\mathrm{n}=120)\end{array}$ & $\begin{array}{c}\text { A20 } \\
(n=483)\end{array}$ & $\begin{array}{c}\mathrm{R} 10 \\
(\mathrm{n}=944)\end{array}$ & $\begin{array}{c}\mathrm{E} 10+\mathrm{A} 10 \rightarrow \\
\mathrm{E} 10+\mathrm{A} 10 \\
(\mathrm{n}=28)\end{array}$ & $\begin{array}{c}\mathrm{A} 20 \rightarrow \\
\mathrm{E} 10+\mathrm{A} 20 \\
(\mathrm{n}=124)\end{array}$ & $\begin{array}{c}\text { A20 } \rightarrow \\
\text { A40 } \\
(\mathrm{n}=126)\end{array}$ & $\begin{array}{c}\mathrm{R} 10 \rightarrow \\
\mathrm{E} 10+\mathrm{A} 20 \\
(\mathrm{n}=234)\end{array}$ & $\begin{array}{c}\mathrm{R} 10 \rightarrow \\
\mathrm{R} 20 \\
(\mathrm{n}=206)\end{array}$ \\
\hline Men & $49(40.8)$ & $230(47.6)$ & 455 (48.2) & $14(50.0)$ & $69(55.6)$ & $63(50.0)$ & $111(47.4)$ & 107 (51.9) \\
\hline Women & $71(59.2)$ & $253(52.4)$ & 489 (51.8) & $14(50.0)$ & $55(44.4)$ & $63(50.0)$ & $123(52.6)$ & $99(48.1)$ \\
\hline Age (yrs) & $60.4 \pm 9.4$ & $59.6 \pm 10.2$ & $59.9 \pm 9.7$ & $61.9 \pm 8.7$ & $59.6 \pm 10.9$ & $58.2 \pm 10.9$ & $59.1 \pm 10.2$ & $57.6 \pm 10.1$ \\
\hline \multicolumn{9}{|l|}{ Race } \\
\hline $\begin{array}{c}\text { American Indian/ } \\
\text { Alaska Native }\end{array}$ & $1(0.8)$ & $1(0.2)$ & 0 & 0 & 0 & $1(0.8)$ & 0 & 0 \\
\hline Asian & 0 & 0 & 0 & 0 & 0 & 0 & 0 & 0 \\
\hline Black & $4(3.3)$ & $11(2.3)$ & $28(3.0)$ & $2(7.1)$ & $3(2.4)$ & $3(2.4)$ & $9(3.8)$ & $8(3.9)$ \\
\hline Multiracial & $2(1.7)$ & $6(1.2)$ & 18 (1.9) & 0 & $1(0.8)$ & 0 & $3(1.3)$ & $2(1.0)$ \\
\hline White & 113 (94.2) & $465(96.3)$ & 897 (95.0) & $26(92.9)$ & $120(96.8)$ & $122(96.8)$ & 222 (94.9) & $196(95.1)$ \\
\hline Unknown & 0 & 0 & $1(0.1)$ & 0 & 0 & 0 & 0 & 0 \\
\hline \multicolumn{9}{|l|}{ Ethnicity } \\
\hline Hispanic or Latino & $32(26.7)$ & $112(23.2)$ & $228(24.2)$ & $9(32.1)$ & $31(25.0)$ & $32(25.4)$ & $52(22.2)$ & $55(26.7)$ \\
\hline Not Hispanic or Latino & $88(73.3)$ & $369(76.4)$ & 714 (75.6) & $19(67.9)$ & $92(74.2)$ & $94(74.6)$ & $182(77.8)$ & $151(73.3)$ \\
\hline Unknown & 0 & $2(0.4)$ & $2(0.2)$ & 0 & $1(0.8)$ & 0 & 0 & 0 \\
\hline Body mass index $\left(\mathrm{kg} / \mathrm{m}^{2}\right)$ & $30.3 \pm 5.2$ & $29.6 \pm 5.0$ & $29.6 \pm 5.0$ & $31.9 \pm 5.1$ & $29.1 \pm 4.8$ & $29.7 \pm 4.4$ & $29.8 \pm 5.0$ & $29.0 \pm 5.0$ \\
\hline Metabolic syndrome* & $81(67.5)$ & $310(64.2)$ & $620(65.7)$ & $22(78.6)$ & $80(64.5)$ & $80(63.5)$ & 159 (67.9) & $117(56.8)$ \\
\hline \multicolumn{9}{|l|}{$\mathrm{CVD}^{\dagger}$} \\
\hline No & $59(49.2)$ & $245(50.7)$ & $465(49.3)$ & $15(53.6)$ & $61(49.2)$ & $70(55.6)$ & $116(49.6)$ & $105(51.0)$ \\
\hline Yes & $61(50.8)$ & $238(49.3)$ & $479(50.7)$ & $13(46.4)$ & $63(50.8)$ & $56(44.4)$ & $118(50.4)$ & $101(49.0)$ \\
\hline Diabetes mellitus & $60(50.0)$ & $222(46.0)$ & $451(47.8)$ & $11(39.3)$ & $55(44.4)$ & $57(45.2)$ & 116 (49.6) & $92(44.7)$ \\
\hline
\end{tabular}

Data are presented as $\mathrm{n}(\%)$ or mean $\pm \mathrm{SD}$.

A10/20/40 = atorvastatin $10 \mathrm{mg}, 20 \mathrm{mg}$, or $40 \mathrm{mg}$; E10 = ezetimibe $10 \mathrm{mg}$; R10/20 = rosuvastatin $10 \mathrm{mg}$ or $20 \mathrm{mg}$.

$*$ Having $\geq 3$ of the following 5 characteristics: waist circumference $\geq 102 \mathrm{~cm}$ for men or $\geq 88 \mathrm{~cm}$ for women; triglycerides $\geq 150 \mathrm{mg} / \mathrm{dl}$; HDL-C $<40 \mathrm{mg} / \mathrm{dl}$ in men or $<50 \mathrm{mg} / \mathrm{dl}$ in women; $\geq 130 \mathrm{~mm} \mathrm{Hg}$ systolic blood pressure, $\geq 85 \mathrm{~mm} \mathrm{Hg}$ diastolic blood pressure, or on antihypertensive drug treatment in a subject with a history of hypertension; fasting glucose $\geq 100 \mathrm{mg} / \mathrm{dl}$ or on drug treatment for elevated glucose.

${ }^{\dagger}$ CVD is defined as the National Cholesterol Education Program-Adult Treatment Panel III and American Heart Association/American College of Cardiology guideline definition of "established atherosclerotic vascular disease."

was not unblinded until medical/scientific review was performed, protocol violators were identified, and data were declared final and complete.

The primary efficacy end point variable was the percent change from treated baseline in LDL-C levels at the end of period I. Key secondary end point variables included percent change from treated baseline in LDL-C at the end of period II; percentage of subjects achieving LDL-C $<100$ or $<70 \mathrm{mg} / \mathrm{dl}$ at the end of periods I and II; percent change from treated baseline in other lipids, lipoproteins, and highsensitivity C-reactive protein (hs-CRP) at the end of periods I and II; assessment of safety and tolerability.

Primary and secondary efficacy end point variables were evaluated using the full analysis set population, including all randomized subjects receiving $\geq 1$ dose of blinded study treatment with baseline and $\geq 1$ postbaseline measurement. Because normality was rejected (at the alpha $=0.001$ level) for the primary end point of percent change from baseline in LDL-C levels after period I, the analysis used a prespecified 2-step multiple imputation method ${ }^{5}$ followed by a robust regression approach ${ }^{6,7}$ that included terms for treatment and baseline LDL-C. The robust regression provided iteratively reweighted-least-square means ${ }^{-}$and associated $\mathrm{p}$ values to determine within- and between-treatment effects. Evaluation of the percentage of patients reaching LDL-C targets $<100$ or $<70 \mathrm{mg} / \mathrm{dl}$ used a logistic regression model with terms for treatment and baseline LDL-C categories (3 categories based on tertiles). Odds ratio estimates and $95 \%$ confidence intervals were used to quantify treatment effects. The percent change from baseline in other lipid and lipoprotein parameters (except triglycerides and hs-CRP) was evaluated using the robust regression approach as described previously. The percent change from baseline in log-transformed data for triglycerides and hs-CRP was assessed using a constrained longitudinal data analysis method because of the non-normal distribution seen in previous studies. ${ }^{8}$ As this study design employed the use of serial treatment assessments, a parallel gatekeeping testing approach was applied to control the overall type-I error rate at an $\alpha$ value of 0.05 for comparisons of percent change from baseline in LDL-C after periods I and II. For other evaluations, the false discovery rate was controlled at 5\%. Analysis of prespecified subgroups provided least squares means and $95 \%$ confidence intervals by fitting an analysis of covariance repeated measure model with terms for treatment and baseline LDL-C.

For the primary and secondary efficacy end points, with a sample size of approximately 1,500 patients planned for randomization, the study was anticipated to have at least 90\% power to demonstrate a difference between ezetimibe coadministered with atorvastatin and the comparative atorvastatin or rosuvastatin monotherapy, assuming a drop-out rate of $\sim 8 \%$, a SD of $20 \%$ ( $\alpha$-level of 0.045 [period I] or 
Table 2

Baseline parameters (all randomized subjects)

\begin{tabular}{|c|c|c|c|c|c|c|c|c|}
\hline Parameter & \multicolumn{3}{|c|}{ Period I } & \multicolumn{5}{|c|}{ Period II } \\
\hline LDL-C $(\mathrm{mg} / \mathrm{dl})^{\dagger}$ & $121 \pm 18$ & $120 \pm 17$ & $121 \pm 18$ & $107 \pm 37$ & $119 \pm 16$ & $121 \pm 21$ & $119 \pm 16$ & $120 \pm 17$ \\
\hline Total cholesterol (mg/dl) & $203 \pm 25$ & $203 \pm 23$ & $205 \pm 24$ & $190 \pm 46$ & $202 \pm 23$ & $203 \pm 25$ & $204 \pm 24$ & $203 \pm 23$ \\
\hline Non-HDL-C (mg/dl) & $150 \pm 25$ & $150 \pm 22$ & $152 \pm 23$ & $137 \pm 42$ & $151 \pm 22$ & $151 \pm 24$ & $151 \pm 21$ & $150 \pm 21$ \\
\hline Apolipoprotein B (mg/dl) & $102 \pm 20$ & $103 \pm 19$ & $104 \pm 19$ & $97 \pm 21$ & $102 \pm 19$ & $103 \pm 18$ & $102 \pm 18$ & $103 \pm 18$ \\
\hline Apolipoprotein AI (mg/dl) & $148 \pm 26$ & $149 \pm 24$ & $148 \pm 24$ & $144 \pm 29$ & $143 \pm 24$ & $147 \pm 23$ & $147 \pm 26$ & $149 \pm 25$ \\
\hline Total/HDL-C & $4.0 \pm 0.9$ & $4.0 \pm 0.9$ & $4.1 \pm 0.9$ & $3.7 \pm 1.0$ & $4.2 \pm 1.0$ & $4.1 \pm 1.0$ & $4.1 \pm 1.0$ & $4.0 \pm 0.9$ \\
\hline LDL-C/HDL-C & $2.4 \pm 0.7$ & $2.4 \pm 0.6$ & $2.4 \pm 0.7$ & $2.1 \pm 0.8$ & $2.5 \pm 0.7$ & $2.5 \pm 0.7$ & $2.4 \pm 0.7$ & $2.4 \pm 0.6$ \\
\hline Non-HDL-C/HDL-C & $3.0 \pm 0.9$ & $3.0 \pm 0.9$ & $3.1 \pm 0.9$ & $2.7 \pm 1.0$ & $3.2 \pm 1.0$ & $3.1 \pm 1.0$ & $3.1 \pm 1.0$ & $3.0 \pm 0.9$ \\
\hline $\begin{array}{l}\text { Apolipoprotein B/ } \\
\text { apolipoprotein AI }\end{array}$ & $0.7 \pm 0.2$ & $0.7 \pm 0.2$ & $0.7 \pm 0.2$ & $0.7 \pm 0.2$ & $0.7 \pm 0.2$ & $0.7 \pm 0.2$ & $0.7 \pm 0.2$ & $0.7 \pm 0.2$ \\
\hline
\end{tabular}

Data are presented as mean $\pm \mathrm{SD}$.

Baseline values refer to values measured at randomization (after atorvastatin $10 \mathrm{mg}$ run-in) for period I and values measured at the end of period I for period II. A10/20/40 = atorvastatin $10 \mathrm{mg}, 20 \mathrm{mg}$, or $40 \mathrm{mg}$; E10 = ezetimibe $10 \mathrm{mg}$; R10/20 = rosuvastatin $10 \mathrm{mg}$ or $20 \mathrm{mg}$.

* Number of all randomized patients evaluated (may vary slightly within each parameter).

${ }^{\dagger}$ LDL-C was calculated using Friedewald method when triglycerides were $<350 \mathrm{mg} / \mathrm{dl}(3.95 \mathrm{mmol} / \mathrm{L})$ and beta quantification ultracentrifugation when triglycerides were $\geq 350 \mathrm{mg} / \mathrm{dl}$.

${ }^{\ddagger}$ Median \pm robust SD (SD calculated as interquartile range/1.075, in which the interquartile range is the third quartile minus the first quartile.

0.050 [period II], 2 sided), and an anticipated number of patients not adequately controlled on atorvastatin $20 \mathrm{mg} /$ day $(50 \%)$ or rosuvastatin $10 \mathrm{mg} / \mathrm{day}(40 \%)$ after period I. These sample size assumptions account for the differences in $n$ values planned for the various treatment arms.

Safety was evaluated using the all-patients-as-treated population, including all randomized subjects who received $\geq 1$ dose of study treatment. Prespecified safety end points of special interest for this study were subject to inferential testing, with $\mathrm{p}$ values and $95 \%$ confidence intervals determined for between-group comparisons using a stratified Miettinen and Nurminen method. ${ }^{9}$ Confidence intervals (95\%) for between-group differences were provided for adverse experience (AE) categories including $\geq 1 \mathrm{AE}$, serious AEs, drug-related AEs, serious drug-related AEs, and discontinuations due to an AE. Assessment of drug causality was determined by the investigator during blinded study treatment, using the criteria of definitely, probably, possibly, probably not, and definitely not related to study drug. An AE was defined as "drug related" if the investigator reported the $\mathrm{AE}$ as being possibly, probably, or definitely due to study drug.

\section{Results}

Of the 1,547 patients randomized, 1,460 (94\%) completed period I. Afterward, 718 subjects with LDL-C levels high enough to be eligible to participate proceeded to period II. Of these, 689 (96\%) completed period II (Figure 2). Study subject discontinuations were 5.6\% during period I (range, $2.5 \%-5.9 \%$ ) and $4.0 \%$ during period II (range, 2.9\%-6.5\%). Baseline characteristics (Table 1) and lipid and lipoprotein levels (Table 2) were generally similar across treatment regimens within each period. Patients randomized to period I had a mean age of 60 years, 53\% were women, $95 \%$ were white, $50 \%$ had CVD, and $47 \%$ had diabetes mellitus ( $0.4 \%$ with type $1,32.4 \%$ with type 2 , and $14.6 \%$ with unknown type). The overall mean baseline LDL-C level was $\sim 120 \mathrm{mg} / \mathrm{dl}$. Baseline characteristics and lipid and lipoprotein levels for uncontrolled patients who continued into period II were similar to those for patients in period I. Overall, mean compliance at the $>95 \%$ level of the prescribed dose was $94 \%$ during atorvastatin $10 \mathrm{mg}$ run-in, 91\% during period I, and $92 \%$ during period II.

For patients with LDL-C levels $\geq 100$ and $\leq 160 \mathrm{mg} / \mathrm{dl}$ after atorvastatin $10 \mathrm{mg}$ run-in, the addition of ezetimibe to atorvastatin $10 \mathrm{mg}$ produced a significantly greater reduction in LDL-C than doubling the atorvastatin dose to $20 \mathrm{mg}$ or switching to rosuvastatin $10 \mathrm{mg}$ (Table 3). Furthermore, the addition of ezetimibe to atorvastatin $10 \mathrm{mg}$ produced significantly greater attainment of LDL-C $<100$ or $<70 \mathrm{mg} / \mathrm{dl}$ (Figure 3) and significantly greater reductions in total cholesterol, non-high-density lipoprotein cholesterol (HDL-C), apolipoprotein B, and LDL-C/HDL-C, total/ HDL-C, and non-HDL-C/HDL-C ratios (Table 3) than atorvastatin $20 \mathrm{mg}$ or rosuvastatin $10 \mathrm{mg}$. The change from baseline in HDL-C, triglycerides, apolipoprotein AI, and hsCRP were similar among treatments (Table 3). Treatment effects were similar for percent change from baseline in LDL-C across all prespecified subgroups of age, gender, race, and diabetic status (Figure 4).

For patients who persisted with LDL-C levels $\geq 100$ and $\leq 160 \mathrm{mg} / \mathrm{dl}$ after an additional 6 weeks on atorvastatin $20 \mathrm{mg}$ or rosuvastatin $10 \mathrm{mg}$ (which followed the atorvastatin $10 \mathrm{mg}$ run-in), the addition of ezetimibe to atorvastatin $20 \mathrm{mg}$ produced significantly greater reductions in LDL-C and significantly greater attainment of LDL-C $<100$ or $<70 \mathrm{mg} / \mathrm{dl}$ than uptitration of atorvastatin to $40 \mathrm{mg}$ 
Table 3

Percent change from treated baseline in assessed parameters (full analysis set population)

\begin{tabular}{|c|c|c|c|c|c|c|c|c|c|c|c|}
\hline \multirow[t]{4}{*}{ Parameter } & \multicolumn{5}{|c|}{ Period I } & \multicolumn{6}{|c|}{ Period II } \\
\hline & \multicolumn{3}{|c|}{ Percent Change from Baseline ${ }^{\dagger}$} & \multicolumn{2}{|c|}{ Treatment Difference } & \multicolumn{4}{|c|}{ Percent Change from Baseline } & \multicolumn{2}{|c|}{ Treatment Difference } \\
\hline & \multirow{2}{*}{$\begin{array}{c}\mathrm{E} 10+\mathrm{A} 10 \\
(\mathrm{n}=120)^{\ddagger}\end{array}$} & \multirow{2}{*}{$\begin{array}{c}\text { A20 } \\
(\mathrm{n}=480)^{\ddagger}\end{array}$} & \multirow{2}{*}{$\begin{array}{c}\mathrm{R} 10 \\
(\mathrm{n}=939)^{\ddagger}\end{array}$} & \multirow{2}{*}{$\begin{array}{c}\mathrm{E} 10+\mathrm{A} 10 \\
\text { vs A20 }\end{array}$} & \multirow{2}{*}{$\begin{array}{l}\mathrm{E} 10+\mathrm{A} 10 \\
\text { vs R10 }\end{array}$} & \multicolumn{2}{|c|}{ A20 $\rightarrow$} & \multicolumn{2}{|c|}{$\mathrm{R} 10 \rightarrow$} & \multirow{2}{*}{$\begin{array}{c}\mathrm{E} 10+\mathrm{A} 20 \\
\text { vs A40 }\end{array}$} & \multirow{2}{*}{$\begin{array}{c}\mathrm{E} 10+\mathrm{A} 20 \\
\text { vs R20 }\end{array}$} \\
\hline & & & & & & $\begin{array}{l}\mathrm{E} 10+\mathrm{A} 20 \\
(\mathrm{n}=124)^{\ddagger}\end{array}$ & $\begin{array}{c}\text { A40 } \\
(\mathrm{n}=124)^{\ddagger}\end{array}$ & $\begin{array}{l}\mathrm{E} 10+\mathrm{A} 20 \\
(\mathrm{n}=231)^{\ddagger}\end{array}$ & $\begin{array}{c}\mathrm{R} 20 \\
(\mathrm{n}=205)^{\ddagger}\end{array}$ & & \\
\hline LDL-C & -22.2 & -9.5 & -13.0 & $-12.7 * * *$ & $-9.1 * * *$ & -17.4 & -6.9 & -17.1 & -7.5 & $-10.5 * * *$ & $-9.5 * * *$ \\
\hline Total cholesterol & -13.5 & -6.4 & -7.7 & $-7.1 * * *$ & $-5.8 * * *$ & -10.7 & -3.8 & -11.8 & -4.5 & $-6.8 * * *$ & $-7.4 * * *$ \\
\hline Non-HDL-C & -18.3 & -8.1 & -10.6 & $-10.1 * * *$ & $-7.6^{* * * *}$ & -15.1 & -5.8 & -16.2 & -6.4 & $-9.3 * * *$ & $-9.8 * * *$ \\
\hline HDL-C & 0.6 & -1.1 & 1.1 & 1.7 & -0.6 & 0.7 & 1.7 & 0.1 & 0.8 & -1.0 & -0.7 \\
\hline Triglycerides ${ }^{\S}$ & -6.0 & -3.9 & -1.1 & -2.1 & -4.9 & -5.9 & -3.1 & -10.2 & -3.2 & -2.8 & $-7.1 *$ \\
\hline Apolipoprotein B & -11.3 & -6.0 & -6.9 & $-5.3 * *$ & $-4.3^{*}$ & -9.8 & -5.4 & -11.9 & -4.1 & -4.3 & $-7.7 * * *$ \\
\hline Apolipoprotein AI & 0.2 & -1.4 & 1.0 & 1.6 & -0.9 & 1.2 & 0.7 & 0.0 & 1.0 & 0.5 & -1.0 \\
\hline LDL-C/HDL-C & -21.7 & -8.0 & -13.9 & $-13.7 * * *$ & $-7.8 * * *$ & -19.0 & -8.7 & -16.5 & -8.2 & $-10.4 * * *$ & $-8.3^{* * * *}$ \\
\hline Total/HDL-C & -13.5 & -5.5 & -8.7 & $-8.1 * * *$ & $-4.8 * *$ & -12.4 & -5.5 & -11.3 & -4.9 & $-6.9 * * *$ & $-6.4 * * *$ \\
\hline $\begin{array}{l}\text { Non-HDL-C/ } \\
\text { HDL-C }\end{array}$ & -17.6 & -7.0 & -11.4 & $-10.6 * * *$ & $-6.2 * *$ & -16.7 & -7.3 & -15.1 & -6.7 & $-9.3 * * *$ & $-8.4 * * *$ \\
\hline $\begin{array}{l}\text { Apolipoprotein B/ } \\
\text { apolipoprotein AI }\end{array}$ & -11.5 & -5.3 & -8.0 & $-6.3 * * *$ & -3.5 & -11.3 & -5.5 & -11.5 & -5.4 & $-5.8 *$ & $-6.1 * *$ \\
\hline Hs-CRP $(\mathrm{mg} / \mathrm{L})^{\S}$ & -10.5 & -6.6 & -9.0 & -3.9 & -1.5 & -19.5 & -6.4 & -10.9 & 0.7 & -13.1 & -11.6 \\
\hline
\end{tabular}

$\mathrm{A} 10 / 20 / 40=$ atorvastatin $10 \mathrm{mg}, 20 \mathrm{mg}$, or $40 \mathrm{mg}$; E10 = ezetimibe $10 \mathrm{mg}$; R10/20 = rosuvastatin $10 \mathrm{mg}$ or $20 \mathrm{mg}$.

$* \mathrm{p}<0.05 ; * * \mathrm{p}<0.01 ; * * * \mathrm{p}<0.001$.

${ }^{\dagger}$ Iteratively reweighted-least squares means (all values except triglycerides and hs-CRP), which are M-estimates based on the method by Huber ${ }^{6}$; $95 \%$ confidence interval and $\mathrm{p}$ value were obtained from fitting a robust regression model with terms for treatment and baseline, after imputing missing values (based on the method by Rubin ${ }^{5}$ ).

${ }^{\ddagger} \mathrm{n}=$ Number of all randomized patients evaluated (may vary slightly within each parameter). Includes patients who may only have either a baseline or an end point observation and those who have both.

${ }^{\S}$ Least squares means based on analysis of log-transformed data, using a constrained longitudinal data analysis model with the log-transformed baseline and log-transformed postbaseline measurements in the response vector and with fixed effects for treatment, time, and the interaction of time by treatment.

(Table 3, Figure 3). Switching from rosuvastatin $10 \mathrm{mg}$ to ezetimibe plus atorvastatin $20 \mathrm{mg}$ produced significantly greater reductions in LDL-C and attainment of LDL-C $<100$ or $<70 \mathrm{mg} / \mathrm{dl}$ than uptitration of rosuvastatin to $20 \mathrm{mg}$ (Table 3, Figure 3). The addition of ezetimibe to atorvastatin $20 \mathrm{mg}$ also produced significantly greater reductions in total cholesterol, non-HDL-C, and all measured lipid and lipoprotein ratios than either atorvastatin $40 \mathrm{mg}$ or rosuvastatin $20 \mathrm{mg}$ (Table 3). The change from treated baseline in apolipoprotein $\mathrm{B}$ and triglycerides with ezetimibe plus atorvastatin $20 \mathrm{mg}$ was significantly greater than rosuvastatin $20 \mathrm{mg}$ but similar to atorvastatin $40 \mathrm{mg}$. No significant between-treatment differences were seen for change from treated baseline in HDL-C, apolipoprotein AI, or hs-CRP. Treatment effects were similar for percent change from baseline in LDL-C across prespecified subgroup categories of age, gender, race, and diabetic status (Figure 4).

Ezetimibe plus atorvastatin $(10 \mathrm{mg}$ or $20 \mathrm{mg}$ ), atorvastatin monotherapy (10 mg, $20 \mathrm{mg}$, or $40 \mathrm{mg}$ ), and rosuvastatin monotherapy (10 mg or $20 \mathrm{mg}$ ) were generally well tolerated during this 18 -week study (Table 4). Overall, at least $1 \mathrm{AE}$ occurred in $12.6 \%$ of patients during period I and $11.1 \%$ of patients during period II. No patient in any treatment group experienced a serious drug-related AE. No meaningful treatment differences were observed in the percentage of patients who experienced any $\mathrm{AE}$, any drugrelated $\mathrm{AE}$, any serious $\mathrm{AE}$, or who discontinued study drug because of an $\mathrm{AE}$.
Comparisons of treatment regimens during period I showed a similar incidence of $\geq 1 \mathrm{AE}$, drug-related AEs, and serious AEs (Table 4). For period II, the incidence of $\geq 1$ $\mathrm{AE}$, drug-related AEs, and serious AEs were similar for patients who received ezetimibe added to atorvastatin $20 \mathrm{mg}$ versus atorvastatin doubling to $40 \mathrm{mg}$. Comparing patients switching from rosuvastatin $10 \mathrm{mg}$ (period I) to ezetimibe plus atorvastatin $20 \mathrm{mg}$ versus rosuvastatin doubling to $20 \mathrm{mg}$, the incidence of drug-related and serious AEs were similar, whereas a numerically greater incidence of $\geq 1 \mathrm{AE}$ was seen with ezetimibe plus atorvastatin $20 \mathrm{mg}$ (Table 4). This difference was associated with a greater number of musculoskeletal and connective tissue disorder events, none of which were myopathy (8 patients [3.5\%] vs 1 patient $[0.5 \%])$. No specific $\mathrm{AE}$ was experienced by $>3$ patients within any treatment group, and individual AEs were not indicative of a pattern suggesting a clinically meaningful difference. Details of investigator-reported, drug-related AEs occurring during period I (43 patients total) and period II (16 patients total) are listed in Table 4.

The incidence of prespecified AEs of special interest was low, with no significant difference seen among the groups (Table 4). The most frequently reported $\mathrm{AE}$ of special interest during period I and II was gastrointestinal related. No patient in any treatment group experienced hepatitisrelated or gall bladder-related AEs or met the Hy's law criteria for potential drug-induced liver injury. ${ }^{10}$ No subject experienced postbaseline creatine kinase elevations $\geq 10 \times$ 


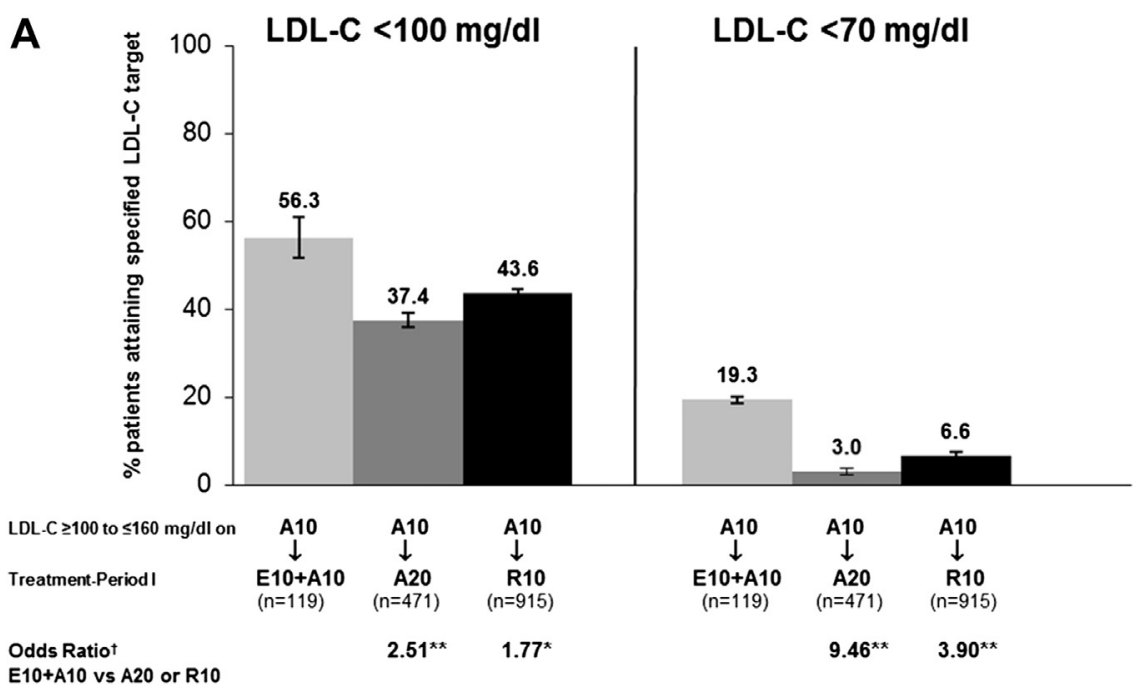

B

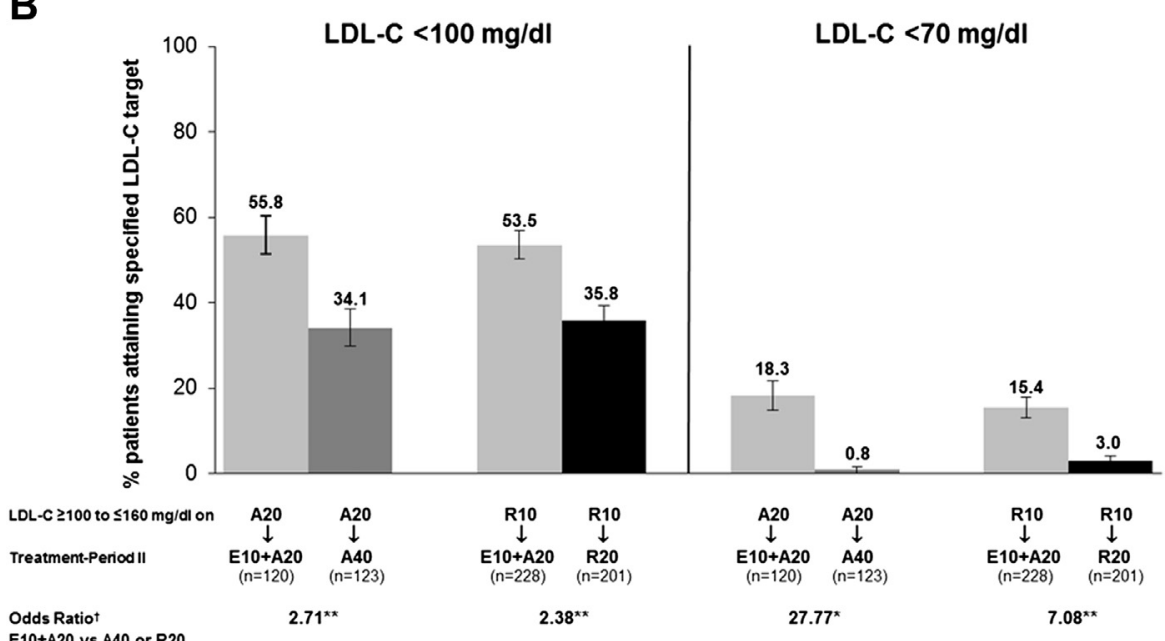

Figure 3. (A) Percent attainment of prespecified LDL-C target after 6 weeks-period I. ${ }^{\dagger}$ Ratio of the predictive odds of achieving LDL-C level on E10 + A10 versus either A20 or R10. ${ }^{*} \mathrm{p}<0.01 ; * * \mathrm{p}<0.001$. (B) Percent attainment of prespecified LDL-C target after 6 weeks-period II. ${ }^{\dagger}$ Ratio of the predictive odds of achieving LDL-C level on E10 + A20 versus either A40 or R20. *p <0.01; **p <0.001. A10/20/40 = atorvastatin $10 \mathrm{mg}, 20 \mathrm{mg}$, or $40 \mathrm{mg}$; E10 = ezetimibe $10 \mathrm{mg}$; R10/20 = rosuvastatin $10 \mathrm{mg}$ or $20 \mathrm{mg}$.

the ULN with or without associated muscle symptoms during period I or II.

A total of 4 patients experienced consecutive alanine aminotransferase or aspartate aminotransferase values $\geq 3 \times$ the ULN during period I or II. During period I, 2 patients receiving rosuvastatin $10 \mathrm{mg}$ treatment experienced consecutive elevations in alanine aminotransferase $\geq 3 \times$ the ULN (mild intensity) during the last week of treatment. One of the 2 enzyme elevations was reported as related to study drug, and both patients discontinued treatment and withdrew from the study. During period II, 2 patients experienced elevated liver enzymes. One patient in the atorvastatin $20 \mathrm{mg}$ uptitrated to atorvastatin $40 \mathrm{mg}$ group had an elevated alanine aminotransferase result $\geq 3 \times$ the ULN, which was considered of mild intensity and not related to study drug. A second patient who switched from rosuvastatin $10 \mathrm{mg}$ in period I to ezetimibe $10 \mathrm{mg}$ plus atorvastatin
$20 \mathrm{mg}$ in period II experienced consecutive elevations of alanine aminotransferase and aspartate aminotransferase $\geq 10 \times$ the ULN, which were reported by the investigator as AEs of moderate severity and not considered to be related to study medication. AEs experienced by both patients occurred at the end of period II, and both patients completed the study without interruption or discontinuation of study drug.

\section{Discussion}

This clinical trial examined various lipid treatment options in patients at high CVD risk who did not achieve LDL-C treatment targets during 2 treatment periods. One unique aspect of the study was its "real-life" study design. The study began by requiring initial therapy with atorvastatin $10 \mathrm{mg} /$ day as run-in before randomization. This reflects 
Table 4

Summary of safety data (all patients as treated)

\begin{tabular}{|c|c|c|c|c|c|c|c|c|c|c|c|c|c|c|c|c|}
\hline \multirow[t]{3}{*}{ 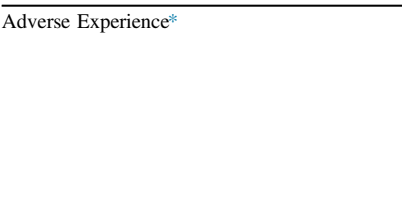 } & \multicolumn{7}{|c|}{ Period I } & \multicolumn{9}{|c|}{ Period II } \\
\hline & \multicolumn{3}{|c|}{ Number $(\%)$ of Events } & \multicolumn{4}{|c|}{ Difference in \% of Events } & \multicolumn{5}{|c|}{ Number (\%) of Events) } & \multicolumn{4}{|c|}{ Difference in \% of Events } \\
\hline & $\begin{array}{l}\mathrm{E} 10+\mathrm{A} 10 \\
(\mathrm{n}=\mathrm{A20})^{*}\end{array}$ & $\begin{array}{c}\mathrm{A} 20 \\
(\mathrm{n}=480)^{*}\end{array}$ & $\begin{array}{c}\mathrm{R} 10 \\
(\mathrm{n}=939)^{*}\end{array}$ & $\begin{array}{l}\text { E10 + A10 vs A20, } \\
\text { Mean (95\% Cl) }\end{array}$ & $\mathrm{p}^{*}$ & $\begin{array}{l}\text { E10 + A10 vs R10, } \\
\text { Mean (95\% Cl) }\end{array}$ & $\mathrm{p}^{*}$ & $\begin{array}{c}\mathrm{E} 10+\mathrm{A} 10 \\
\vdots \\
\mathrm{E} 10+\mathrm{A} 10 \\
(\mathrm{n}=28)^{*}\end{array}$ & $\begin{array}{l}\mathrm{E} 10+\mathrm{A} 20 \\
(\mathrm{n}=124)^{*}\end{array}$ & $\underbrace{}_{\substack{\text { A40 } \\
(\mathrm{n}=124)^{*}}}$ & $\begin{array}{l}\mathrm{R} 10 \\
\mathrm{E} 10+\mathrm{A} 20 \\
(\mathrm{n}=231)^{*}\end{array}$ & ${ }_{\substack{\mathrm{R} 20 \\
(\mathrm{n}=205)^{*}}}$ & $\begin{array}{l}\text { E10 + A20 vs A40, } \\
\text { Mean }(95 \% \mathrm{Cl})^{\dagger}\end{array}$ & $\mathrm{p}^{\mathrm{t}}$ & $\begin{array}{l}\text { E10+ A20 vs R20, } \\
\text { Mean }(95 \% \text { Cl) }\end{array}$ & $\mathrm{p}^{\dagger}$ \\
\hline \multicolumn{17}{|l|}{ All patients } \\
\hline$\geq 1 \mathrm{AE}$ & $9(7.5)$ & $57(11.9)$ & $128(13.6)$ & $-4.4(-9.2,2.2)$ & & $-6.1(-10.4,0.3)$ & & $1(3.6)$ & $11(8.9)$ & $13(10.5)$ & $36(15.6)$ & $18(8.8)$ & $-1.6(-9.4,6.0)$ & & $6.8(0.6,13.0)$ & \\
\hline Drug related $^{\ddagger}$ & $1(0.8)$ & $15(3.1)$ & $27(2.9)$ & $-2.3(-4.5,1.6)$ & & $-2.0(-3.6,1.7)$ & & $1(3.6)$ & $2(1.6)$ & $3(2.4)$ & $8(3.5)$ & $2(1.0)$ & $-0.8(-5.5,3.6)$ & & $2.5(-0.4,5.8)$ & \\
\hline Serious & 0 & $3(0.6)$ & $10(1.1)$ & $-0.6(-0.8,2.5)$ & & $-1.1(-1.9,2.0)$ & & 0 & $2(1.6)$ & $2(1.6)$ & $5(2.2)$ & $1(0.5)$ & $0.0(-4.3,4.3)$ & & $1.7(-0.7,4.5)$ & \\
\hline 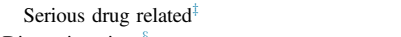 & 0 & 0 & 0 & $0.0(-0.8,3.1)$ & & $0.0(-0.4,3.1)$ & & 0 & 0 & 0 & 0 & 0 & $0.0(-3.0,3.0)$ & & $0.0(-1.8,1.6)$ & \\
\hline Discontinuations $^{8}$ & $1(0.8)$ & $9(1.9)$ & $11(1.2)$ & $-1.0(-2.9,2.8)$ & & $-0.3(-1.5,3.4)$ & & 0 & $1(0.8)$ & $1(0.8)$ & $1(0.4)$ & $1(0.5)$ & $0.0(-3.7,3.7)$ & & $-0.1(-2.3,2.0)$ & \\
\hline $\begin{array}{l}\text { Deaths } \\
\text { Prespecified AEs } \|\end{array}$ & 0 & 0 & \multirow{2}{*}{\multicolumn{12}{|c|}{ Prespecified AEs" $\|^{\|}$}} & & \\
\hline $\begin{array}{l}\text { Prespecified AEs } \\
\text { Alaninie aminotransferase }>3 \times \text { ULN }^{\natural}\end{array}$ & 0 & 0 & & $0(-0.8,3.1) \quad-\quad-2$ & & & 0.613 & 0 & & & & & & & & \\
\hline $\begin{array}{l}\text { Alannine amintoranssterase } \geq 3 \times \text { ULN } \\
\text { Alanine aminotransferase } \geq 5 \times \text { ULN }\end{array}$ & 0 & 0 & $\begin{array}{l}2(0.2) \\
1(0.1)\end{array}$ & $\begin{array}{l}0(-0.8,3.1) \\
0(-0.8,3.1)\end{array}$ & $>0.999$ & $\begin{array}{l}-0.2(-0.8,2.9) \\
-0.1(-0.6,3.0)\end{array}$ & $\begin{array}{l}0.613 \\
0.721\end{array}$ & 0 & 0 & $1(0.8)$ & $\begin{array}{l}1(0.4) \\
1(0.4)\end{array}$ & 0 & $\begin{array}{r}-0.8(-4.4,2.2) \\
0.0(-3.0,3.0)\end{array}$ & $>0.999$ & $\begin{array}{l}0.4(-1.4,2.4) \\
0.4(-1.4,2.4)\end{array}$ & $\begin{array}{l}0.346 \\
0.346\end{array}$ \\
\hline Alanine aminotransferase $\geq 10 \times \mathrm{C}$ & 0 & 0 & $1(0.1)$ & $0(-0.8,3.1)$ & $>0.999$ & $-0.1(-0.6,3.0)$ & 0.721 & 0 & 0 & 0 & $1(0.4)$ & 0 & $0.0(-3.0,3.0)$ & $>0.999$ & $0.4(-1.4,2.4)$ & 0.346 \\
\hline Aspartate aminotransferase $\geq 3 \times \mathrm{ULN}^{\natural}$ & 0 & 0 & 0 & $0(-0.8,3.1)$ & $>0.999$ & $0.0(-0.4,3.1)$ & $>0.999$ & 0 & 0 & 0 & $1(0.4)$ & 0 & $0.0(-3.0,3.0)$ & $>0.999$ & $0.4(-1.4,2.4)$ & 0.346 \\
\hline Aspartate aminotransferase $\geq 5 \times$ ULN & 0 & 0 & 0 & $0(-0.8,3.1)$ & $>0.999$ & $0.0(-0.4,3.1)$ & $>0.999$ & 0 & 0 & 0 & $1(0.4)$ & 0 & $0.0(-3.0,3.0)$ & $>0.999$ & $0.4(-1.4,2.4)$ & 0.346 \\
\hline Aspartate aminotransferase $\geq 10 \times$ ULN & 0 & 0 & 0 & $0(-0.8,3.1)$ & $>0.999$ & $0.0(-0.4,3.1)$ & $>0.999$ & 0 & 0 & 0 & $1(0.4)$ & 0 & $0.0(-3.0,3.0)$ & $>0.999$ & $0.4(-1.4,2.4)$ & 0.346 \\
\hline $\begin{array}{l}\text { Alanine aminotransferase and/or } \\
\text { aspartate aminotransferase } \geq 3 \times \mathrm{ULN}^{4}\end{array}$ & 0 & 0 & $2(0.2)$ & $0(-0.8,3.1)$ & $>0.999$ & $-0.2(-0.8,2.9)$ & 0.613 & 0 & 0 & $1(0.8)$ & $1(0.4)$ & 0 & $-0.8(-4.4,2.2)$ & 0.317 & $0.4(-1.4,2.4)$ & 0.346 \\
\hline $\begin{array}{l}\text { Alanine aminotransferase and/or } \\
\text { aspartate aminotransferase } \geq 5 \times \text { ULN }\end{array}$ & 0 & 0 & $1(0.1)$ & $0(-0.8,3.1)$ & $>0.999$ & $-0.1(-0.6,3.0)$ & 0.721 & 0 & 0 & 0 & $1(0.4)$ & 0 & $0.0(-3.0,3.0)$ & $>0.999$ & $0.4(-1.4,2.4)$ & 0.346 \\
\hline $\begin{array}{l}\text { Alanine aminotransferase and/or } \\
\text { aspartate aminotransferase } \geq 10 \times \text { ULN }\end{array}$ & 0 & 0 & $1(0.1)$ & $0(-0.8,3.1)$ & $>0.999$ & $-0.1(-0.6,3.0)$ & 0.721 & 0 & 0 & 0 & $1(0.4)$ & 0 & $0.0(-3.0,3.0)$ & $>0.999$ & $0.4(-1.4,2.4)$ & 0.346 \\
\hline Gastrointestinal-related $\mathrm{AE}$ & $2(1.7)$ & $12(2.5)$ & $19(2$ & $-0.8(-3.1,3.5)$ & 0.589 & & 0.79 & $1(3.6)$ & $2(1.6)$ & $2(1$ & $2(0.9)$ & $2(1.0)$ & 3) & $>0.999$ & .2) & 05 \\
\hline Allergic reaction or rash $\mathrm{AE}$ & 0 & $2(0.4)$ & $8(0.9)$ & $-0.4(-1.5,2.7)$ & 0.479 & $-0.9(-1.7,2.3)$ & 0.310 & 0 & 0 & $1(0.8)$ & 0 & 0 & $-0.8(-4.4,2.2)$ & 0.317 & $0.0(-1.8,1.6)$ & 0.999 \\
\hline
\end{tabular}

Allergic reaction or rash $\mathrm{AE}$

$\%=$ (number of patients within the $\mathrm{AE}$ category/number of treated patients) $\times 100 ; \mathrm{A} 10 / 20 / 40=$ atorvastatin $10 \mathrm{mg}, 20 \mathrm{mg}$, or $40 \mathrm{mg}$; E10 = ezetimibe $10 \mathrm{mg} ; \mathrm{R} 10 / 20=$ rosuvastatin $10 \mathrm{mg}$ or $20 \mathrm{mg}$

* All-patients-as-treated population; all randomized patients who took at least 1 dose of study medication. For laboratory safety (alanine aminotransferase, aspartate aminotransferase, creatine kinase, and potential Hy's law condition), patients must have taken at least 1 dose of study medication and have at least 1 postbaseline measurement within 14 days of the last dose of study therapy to be included in the analysis.

Confidence intervals and $\mathrm{p}$ values calculated using the Miettinen and Nurminen method.

₹ Determined by the investigator to be related to the drug; assessment of drug causality determined using following criteria: definitely, probably, or possibly related defined as "drug related"; probably not and definitely not related defined as "not related." Investigator-reported

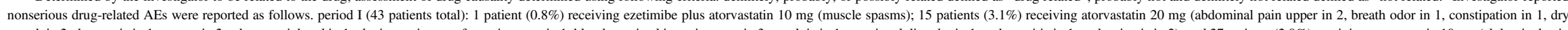

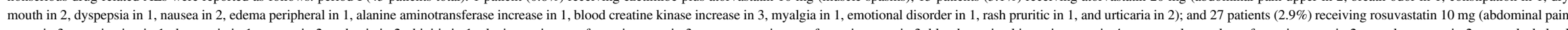

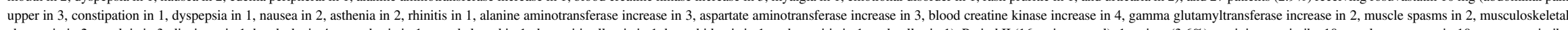

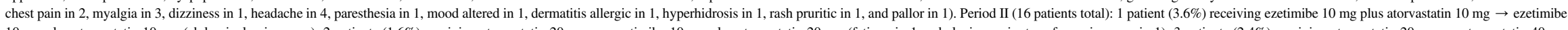

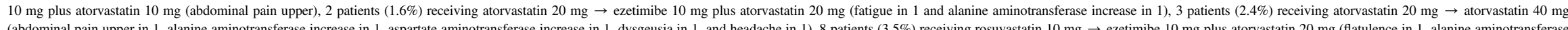

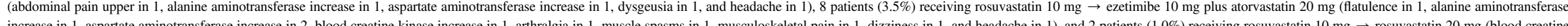
kinase increase in 2).

Study medication withdrawn

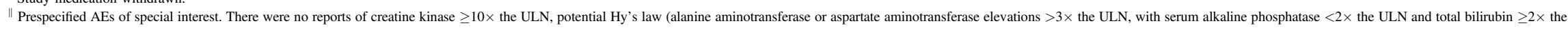
LN), hepatitis-retred

$\uparrow$ Patients with $\geq 2$ consecutive measurements of $\geq 3 \times$ the ULN, a single last measurement of $\geq 3 \times$ the ULN, or a measurement of $\geq 3 \times$ the ULN followed by a measurement of $<3 \times$ the ULN taken $>2$ days after the last dose of study medication. 


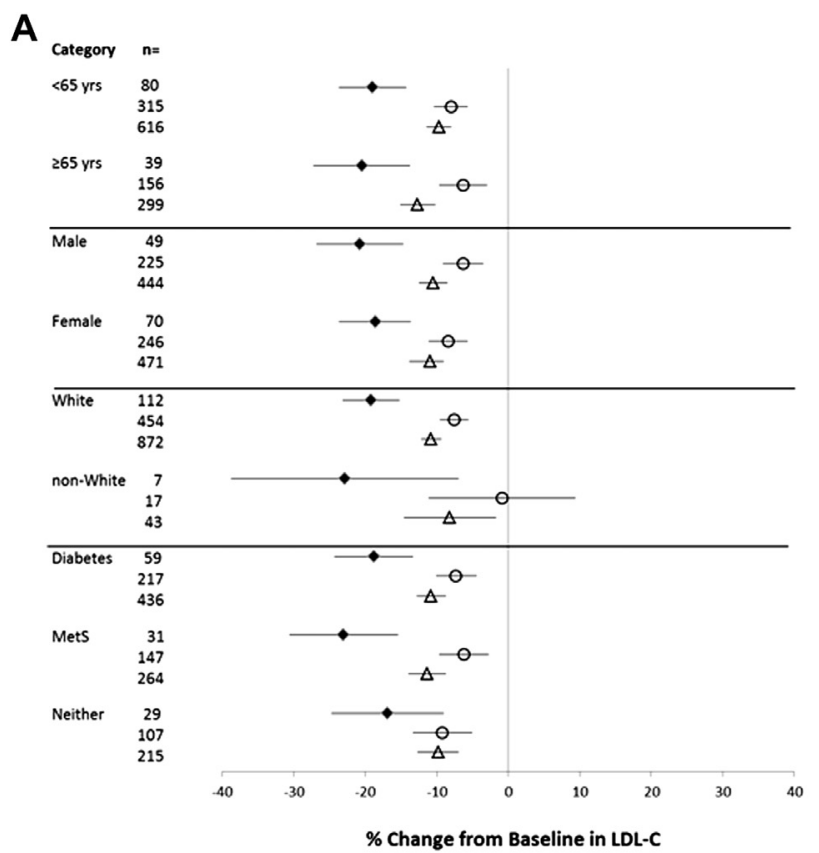

$\rightarrow E 10+$ A10 OA20 $\triangle R 10$

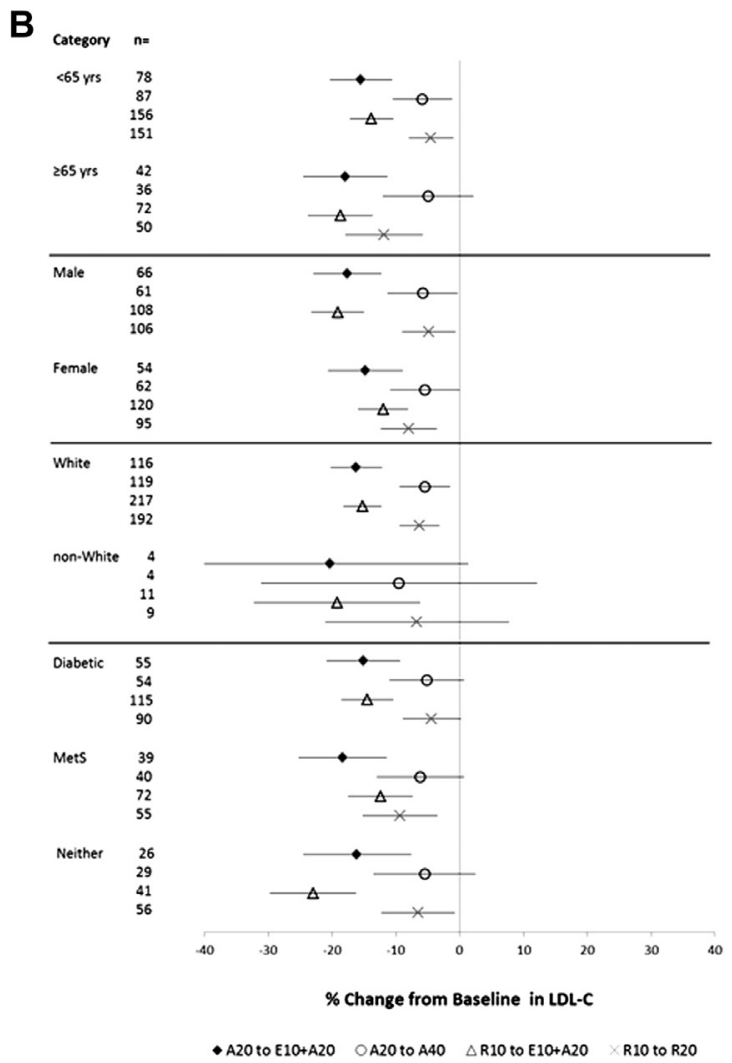

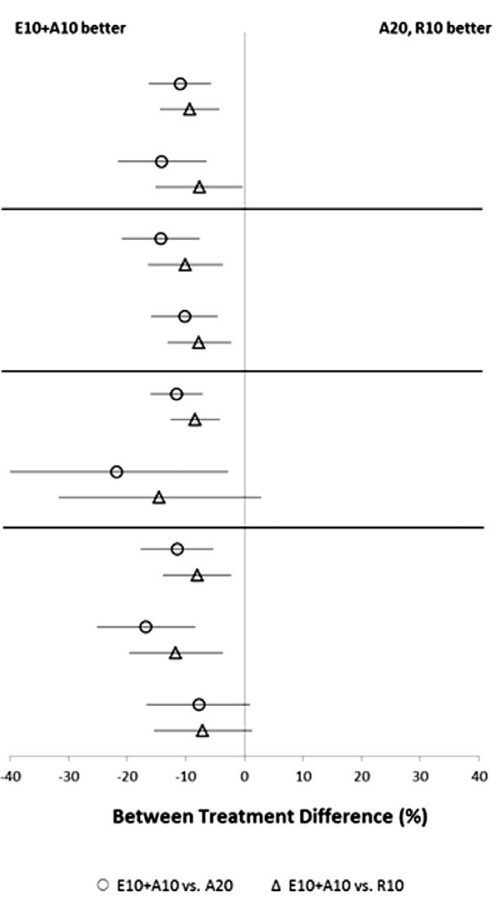

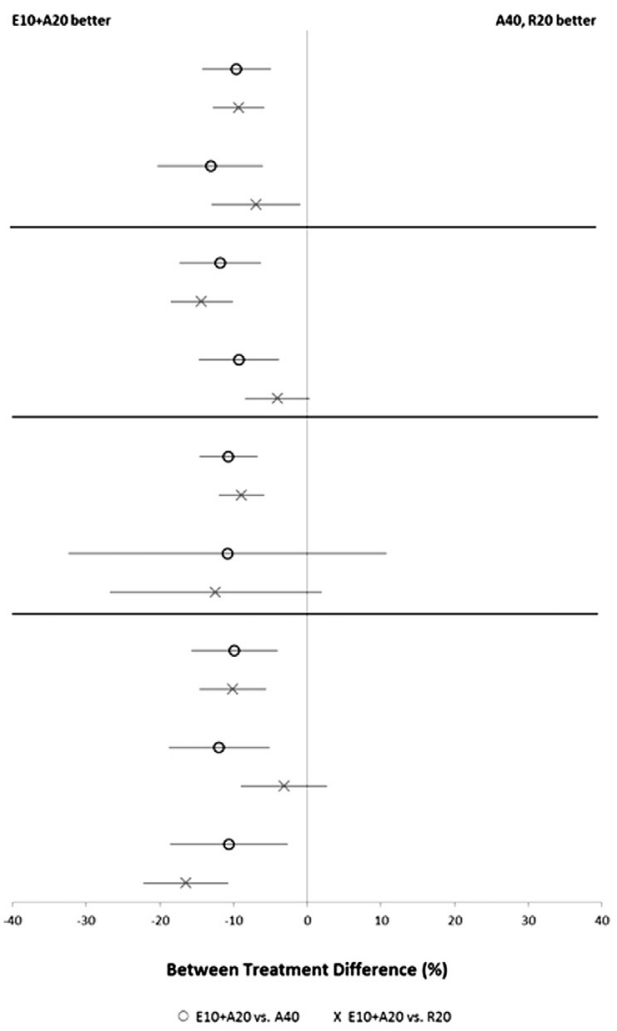

Figure 4. (A) Percent change from treated baseline in LDL-C for prespecified subgroups after 6 weeks-period I. Treatments were (1) ezetimibe plus atorvastatin $10 \mathrm{mg}$ (closed diamonds), (2) atorvastatin $20 \mathrm{mg}$ (open circles), or (3) rosuvastatin $10 \mathrm{mg}$ (open triangles). MetS = subgroup of patients with metabolic syndrome and no diabetes; Neither $=$ no metabolic syndrome or diabetes; $n=$ number of subjects in each subgroup for ezetimibe plus atorvastatin $10 \mathrm{mg}$, atorvastatin $20 \mathrm{mg}$, and rosuvastatin $10 \mathrm{mg}$, respectively. Between-treatment differences within each subgroup are ezetimibe plus atorvastatin $10 \mathrm{mg}$ minus atorvastatin $20 \mathrm{mg}$ (open circles) and ezetimibe plus atorvastatin $10 \mathrm{mg}$ minus rosuvastatin $10 \mathrm{mg}$ (open triangles). (B) Percent change from treated baseline in LDL-C for prespecified subgroups after 6 weeks-period II. Treatments during periods I and II were (1) atorvastatin $20 \mathrm{mg} \rightarrow$ atorvastatin $20 \mathrm{mg}$ plus ezetimibe (closed diamonds), (2) atorvastatin $20 \mathrm{mg} \rightarrow$ atorvastatin $40 \mathrm{mg}$ (open circles), (3) rosuvastatin $10 \mathrm{mg} \rightarrow$ atorvastatin $20 \mathrm{mg}$ plus ezetimibe (open triangles), or (4) rosuvastatin $10 \mathrm{mg} \rightarrow$ rosuvastatin $20 \mathrm{mg}(\times) . \mathrm{n}=$ number of subjects in subgroup for each treatment regimen $(1,2$, 3, 4, as aforementioned). Treatment differences within a subgroup are ezetimibe plus atorvastatin $20 \mathrm{mg}$ minus atorvastatin $40 \mathrm{mg}$ (open circles) and ezetimibe plus atorvastatin $20 \mathrm{mg}$ minus rosuvastatin $20 \mathrm{mg}(\times)$. 
the common clinical practice of prescribing a statin (which is often a generic statin) as the initial pharmacologic therapy to treat hypercholesterolemia in patients at high CVD risk. After the 5 week run-in on atorvastatin $10 \mathrm{mg} /$ day, study subjects who were not at LDL-C treatment target were then randomized to a number of therapeutic approaches, with each being illustrative examples of cholesterol-lowering options often considered for the purpose of achieving LDL-C treatment targets. The study went yet further in evaluating treatment options among those who still did not achieve LDL-C treatment targets, despite initial treatment with atorvastatin $10 \mathrm{mg} /$ day and subsequent adjustment in lipid-altering drug therapy. The findings of this study can be summarized as follows:

1) Among hypercholesterolemic patients at high CVD risk treated with atorvastatin $10 \mathrm{mg}$ /day having LDL$\mathrm{C}$ levels that continued to exceed LDL-C treatment targets (i.e., $\geq 100$ and $\leq 160 \mathrm{mg} / \mathrm{dl}$ ), ezetimibe $10 \mathrm{mg}$ plus atorvastatin $10 \mathrm{mg}$ reduced LDL-C significantly more than doubling atorvastatin from 10 to $20 \mathrm{mg}$ and significantly more than switching atorvastatin $10 \mathrm{mg}$ to rosuvastatin $10 \mathrm{mg}$.

2) Among hypercholesterolemic patients at high CVD risk who had their atorvastatin $10 \mathrm{mg} /$ day doubled to $20 \mathrm{mg} /$ day and who continued to have LDL-C levels that exceeded treatment targets, ezetimibe $10 \mathrm{mg}$ plus atorvastatin $20 \mathrm{mg}$ reduced LDL-C significantly more than doubling atorvastatin 20 to $40 \mathrm{mg}$.

3) Among hypercholesterolemic patients at high CVD risk who had switched from atorvastatin $10 \mathrm{mg} / \mathrm{day}$ to rosuvastatin $10 \mathrm{mg} /$ day and who continued to have LDL-C levels that exceeded treatment targets, switching to ezetimibe $10 \mathrm{mg}$ plus atorvastatin $20 \mathrm{mg}$ reduced LDL-C significantly more than doubling rosuvastatin from 10 to $20 \mathrm{mg}$.

Concomitant with greater LDL-C lowering, relative to comparative treatments, ezetimibe added to atorvastatin $10 \mathrm{mg}$ (period I) or atorvastatin $20 \mathrm{mg}$ (period II) produced significantly greater percent attainment of LDL-C targets of $<100$ or $<70 \mathrm{mg} / \mathrm{dl}^{1,2}$ and produced significantly greater percent reductions in total cholesterol, non-HDL-C, apolipoprotein B (except ezetimibe plus atorvastatin $20 \mathrm{mg}$ vs atorvastatin $40 \mathrm{mg}$ ) and lipid and lipoprotein ratios. These results are consistent with the comparative effects of adding ezetimibe to ongoing statins versus statin titration seen in other studies of moderately high- to high-risk subjects with inadequately controlled LDL-C during statin therapy. ${ }^{11-13}$

Previous studies suggest that doubling of the statin dose typically results in an incremental reduction of 5\% to $7 \%$ from untreated baseline. ${ }^{14}$ This is consistent with the findings of the present study, wherein doubling atorvastatin or rosuvastatin reduced LDL-C by an additional $6.9 \%$ to $9.5 \%$. Switching to a different statin represents a second option for management of hypercholesterolemia. ${ }^{14,15}$ In the present study, switching from atorvastatin $10 \mathrm{mg}$ to rosuvastatin $10 \mathrm{mg}$ resulted in greater LDL-C lowering. Adding ezetimibe to ongoing statin therapy represents yet another therapeutic alternative. ${ }^{16}$ In the present study, addition of ezetimibe to ongoing atorvastatin $10 \mathrm{mg}$ during period I reduced LDL-C by $22 \%$, and adding ezetimibe to atorvastatin $20 \mathrm{mg}$ during period II reduced LDL-C by $17 \%$. Few clinical trials have evaluated the sequential modification of lipid-altering therapy on LDL-C lowering and attainment of treatment targets. ${ }^{17}$ Results from the present trial suggest that statin doubling and ezetimibe add-on treatment strategies produce incremental LDL-C-lowering for patients with persistent LDL-C levels $\geq 100 \mathrm{mg} / \mathrm{dl}$ after 6 weeks of atorvastatin $10 \mathrm{mg}$ (period I) or after atorvastatin $10 \mathrm{mg}$ followed by an additional 6 weeks on atorvastatin $20 \mathrm{mg}$ or rosuvastatin $10 \mathrm{mg}$ (period II).

Study treatment approaches were generally similar with regard to safety and tolerability and generally consistent with previous clinical studies of similar duration. Study limitations include the short duration of the study and a study population that was mostly white, thus limiting the generalizability of study results for long-term therapy or more diverse populations. Additionally, although this trial evaluated the effect of study medications on lipids and other parameters, this study was neither designed to evaluate nor did it evaluate the effect of ezetimibe on CVD outcomes.

Acknowledgment: The authors gratefully acknowledge the contributions of the study investigators and thank Kathleen Newcomb and Martha Vollmer, employees of Merck \& Co. Inc., for manuscript editorial assistance.

\section{Disclosures}

H.E.B. has served as a consultant/advisor for Amarin, AstraZeneca, Bristol-Myers Squibb, Catabasis, Daiichi Sankyo, Eisai, Merck, Vivus, WPU, and Zeomedex; received grants/grants pending to his institution from Amarin, Amgen, Ardea Inc., Arena Pharmaceuticals, Boehringer Ingelheim, California Raisin Board, Cargill Incorporated, Catabasis, Eisai, Elcelyx, Esperion, Essentialis, Forest, Gilead, Given, GlaxoSmithKline, High Point Pharmaceuticals, LLC, Hoffman LaRoche, Home Access, Merck, Micropharma Limited, Nektar, Novartis, Novo Nordisk, Omthera, Orexigen Therapeutics, Pfizer, Pozen, Regeneron, Stratum Nutrition, Takeda, TIMI, Transtech Pharma, Inc., Trygg Pharmaceuticals, TWI Bio, Vivus, WPU, Xoma, and Zeomedex; and received speakers' honoraria from Amarin, Daiichi Sankyo, Eisai, Merck, and Vivus.

M.A. has served as a consultant for Aegerion, Genzyme, Merck, and Roche; received research grants from Aegerion, Dr. Reddys, Merck, Pfizer, Roche, and Sanofi; and received speakers' honoraria from AstraZeneca, Mediolanum, and Aegerion.

C.M. has received research grants and speakers' honoraria from Merck.

D.M-.W. served as a consultant/advisor for AstraZeneca, Bristol-Myers Squibb, Merck, and Novartis.

A.D.P. received a research grant from Merck for this study.

R.S.L., P.B., J.T., R.L., and H.G. are current or former employees of Merck Sharp \& Dohme Inc. (Whitehouse Station, New Jersey) and may own stock or stock options in the company. 
M.F. has served as a board member for Genzyme, Kowa, Merck, Recordati, and Sanofi-Aventis; consultant for Abbott, Boehringer Ingelheim, Kowa, Merck, SanofiAventis, Recordati, Roche, SMB; and received speakers' honoraria from Abbott, Kowa, Merck, Pfizer, Roche, Recordati, Sanofi-Aventis, and SMB.

1. Catapano AL, Reiner Z, De Backer G, Graham I, Taskinen MR, Wiklund O, Agewall S, Alegria E, Chapman MJ, Durrington P, Erdine S, Halcox J, Hobbs R, Kjekshus J, Filardi PP, Riccardi G, Storey RF, Wood D. ESC/EAS Guidelines for the management of dyslipidaemias The Task Force for the management of dyslipidaemias of the European Society of Cardiology (ESC) and the European Atherosclerosis Society (EAS). Atherosclerosis 2011;217:3-46.

2. Grundy SM, Cleeman JI, Merz CN, Brewer HB Jr, Clark LT, Hunninghake DB, Pasternak RC, Smith SC Jr, Stone NJ. Implications of recent clinical trials for the National Cholesterol Education Program Adult Treatment Panel III Guidelines. J Am Coll Cardiol 2004;44:720-732.

3. Graham I, Atar D, Borch-Johnsen K, Boysen G, Burell G, Cifkova R, Dallongeville J, De Backer G, Ebrahim S, Gjelsvik B, Herrmann-Lingen C, Hoes A, Humphries S, Knapton M, Perk J, Priori SG, Pyorala K, Reiner Z, Ruilope L, Sans-Menendez S, Op Reimer WS, Weissberg P, Wood D, Yarnell J, Zamorano JL, Walma E, Fitzgerald T, Cooney MT, Dudina A, Vahanian A, Camm J, De Caterina R, Dean V, Dickstein K, FunckBrentano C, Filippatos G, Hellemans I, Kristensen SD, McGregor K, Sechtem U, Silber S, Tendera M, Widimsky P, Zamorano JL, Altiner A, Bonora E, Durrington PN, Fagard R, Giampaoli S, Hemingway H, Hakansson J, Kjeldsen SE, Larsen L, Mancia G, Manolis AJ, Orth-Gomer K, Pedersen T, Rayner M, Ryden L, Sammut M, Schneiderman N, Stalenhoef AF, Tokgozoglu L, Wiklund O, Zampelas A. European guidelines on cardiovascular disease prevention in clinical practice: full text. Fourth Joint Task Force of the European Society of Cardiology and other societies on cardiovascular disease prevention in clinical practice (constituted by representatives of nine societies and by invited experts). Eur J Cardiovasc Prev Rehabil 2007;14(Suppl 2):S1-113.

4. Smith SC Jr, Allen J, Blair SN, Bonow RO, Brass LM, Fonarow GC, Grundy SM, Hiratzka L, Jones D, Krumholz HM, Mosca L, Pasternak RC, Pearson T, Pfeffer MA, Taubert KA. AHA/ACC guidelines for secondary prevention for patients with coronary and other atherosclerotic vascular disease: 2006 update. Endorsed by the National Heart, Lung, and Blood Institute. J Am Coll Cardiol 2006;47:2130-2139.

5. Rubin DB. Multiple Imputation for Nonresponse in Surveys. John Wiley \& Sons, Inc, 1987.

6. Huber PJ. The 1972 Wald Memorial Lectures. Robust regression: asymptotics, conjectures, and Monte Carlo. Ann Stat 1973;1:799-821.
7. Mehrotra DV, Li X, Liu J, Lu K. Analysis of longitudinal clinical trials with missing data using multiple imputation in conjunction with robust regression. Biometrics 2012;68:1250-1259.

8. Liang KY, Zeger SL. Longitudinal data analysis of continuous and discrete responses for pre-post designs. Sankya 2000;62:134-148.

9. Miettinen O, Nurminen M. Comparative analysis of two rates. Stat Med $1985 ; 4: 213-226$.

10. U.S. Department of Health and Human Services Food and Drug Administration Center for Drug Evaluation and Research (CDER). Guidance for Industry: Drug-Induced Liver Injury: Premarketing Clinical Evaluation. 2009 http://www.regulations.gov/\#!documentDetail; $D=F D A-2008-D-0128-0005$.

11. Bays HE, Davidson MH, Massaad R, Flaim D, Lowe RS, Tershakovec AM, Jones-Burton C. Safety and efficacy of ezetimibe added on to rosuvastatin 5 or $10 \mathrm{mg}$ versus up-titration of rosuvastatin in patients with hypercholesterolemia (the ACTE Study). Am J Cardiol 2011;108: 523-530.

12. Conard SE, Bays HE, Leiter LA, Bird SR, Rubino J, Lowe RS, Tomassini JE, Tershakovec AM. Efficacy and safety of ezetimibe added on to atorvastatin $(20 \mathrm{mg})$ versus uptitration of atorvastatin (to $40 \mathrm{mg}$ ) in hypercholesterolemic patients at moderately high risk for coronary heart disease. Am $J$ Cardiol 2008;102: 1489-1494.

13. Leiter LA, Bays H, Conard S, Bird S, Rubino J, Hanson ME, Tomassini JE, Tershakovec AM. Efficacy and safety of ezetimibe added on to atorvastatin $(40 \mathrm{mg})$ compared with uptitration of atorvastatin (to 80 $\mathrm{mg}$ ) in hypercholesterolemic patients at high risk of coronary heart disease. Am J Cardiol 2008;102:1495-1501.

14. Jones PH, Davidson MH, Stein EA, Bays HE, McKenney JM, Miller E, Cain VA, Blasetto JW. Comparison of the efficacy and safety of rosuvastatin versus atorvastatin, simvastatin, and pravastatin across doses (STELLAR* Trial). Am J Cardiol 2003;92: $152-160$.

15. Ballantyne CM, Bertolami M, Hernandez Garcia HR, Nul D, Stein EA, Theroux P, Weiss R, Cain VA, Raichlen JS. Achieving LDL cholesterol, non-HDL cholesterol, and apolipoprotein B target levels in highrisk patients: Measuring Effective Reductions in Cholesterol Using Rosuvastatin therapY (MERCURY) II. Am Heart J 2006;151: 975-979.

16. Toth PP, Catapano A, Tomassini JE, Tershakovec AM. Update on the efficacy and safety of combination ezetimibe plus statin therapy. Clin Lipidol 2010;5:655-684.

17. Insull W Jr, Ghali JK, Hassman DR, Y As JW, Gandhi SK, Miller E. Achieving low-density lipoprotein cholesterol goals in high-risk patients in managed care: comparison of rosuvastatin, atorvastatin, and simvastatin in the SOLAR trial. Mayo Clin Proc 2007;82:543-550. 